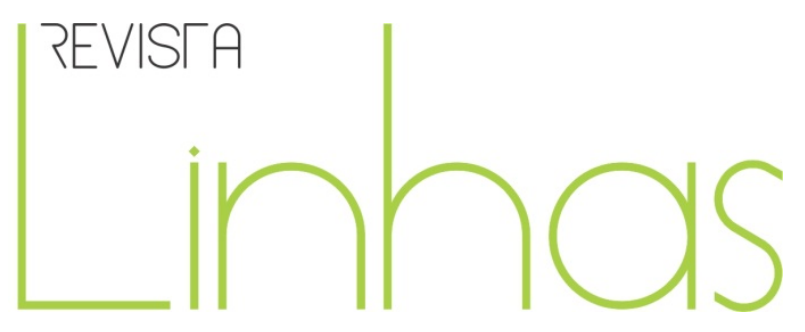

\title{
Pela preservação da memória e do patrimônio educacional militar: a criação do Centro de Memória do Ensino Militar na Universidade da Força Aérea
}

\begin{abstract}
Resumo
Este artigo tem como objetivo relatar o processo de implantação do Centro de Memória do Ensino Militar da Universidade da Força Aérea (CME/UNIFA) e seus desafios. Ele foi criado, inicialmente, com a finalidade de preservar o patrimônio escolar da Aeronáutica, de modo a aproveitar esses saberes, perdidos no tempo, para a compreensão e a melhoria das práticas educacionais do presente. Todavia, como muitos dos documentos relevantes sobre a história dessa Instituição, bem como do Exército e da Marinha do Brasil, estivessem sendo descartados, além dos relacionados ao ensino militar nessas três Forças, o Centro tornou-se um lugar de preservação de fontes documentais relativas à história militar e à história do ensino militar, em geral.
\end{abstract}

Palavras-chave: Patrimônio escolar; Centro de documentação escolar; Memória da educação; História da educação militar; História militar.

\author{
Maria Luiza Cardoso \\ Doutora em Educação pela \\ Universidade de São Paulo - USP \\ marialuizacardoso@terra.com.br
}

\section{Para citar este artigo:}

CARDOSO, Maria Luiza. Pela preservação da memória e do patrimônio educacional militar: a criação do Centro de Memória do Ensino Militar na Universidade da Força Aérea. Revista Linhas, Florianópolis, v. 15, n. 28, p. 127-153, jan./jun. 2014. 


\title{
For the preservation of the memory and the military educational patrimony: the creation of the Center for Memory of Military Education at the University of the Air Force
}

\begin{abstract}
This article aims to describe the process of implementation of the Memory Center of Military Education at the University of the Air Force and its challenges. It was created, initially, with the purpose of preserving the heritage school of the Brazilian Air Force, to take advantage of this knowledge, lost in time, for understanding and improving educational practices of the present. However, as many of the relevant documents on the history of this Institution, as well as the Army and Navy of Brazil were being discarded, beyond those related to military education in these three Forces, the Center has become a place of preservation of documentary sources relating to the military history and the history of military education in general.
\end{abstract}

Keywords: School heritage; Center of school documentation; Memory of Education; History of military education; Military history. 
A Universidade da Força Aérea (UNIFA) é a única universidade federal militar do Brasil. Foi criada na década de $1980^{1}$, época em que o País sofreu grandes mudanças políticas. O Presidente da República era o General de Exército João Baptista de Oliveira Figueiredo e o seu Vice era o político Aureliano Chaves. O Ministro da Aeronáutica do Presidente Figueiredo era o Tenente Brigadeiro do Ar Délio Jardim de Mattos, seu amigo pessoal.

A UNIFA foi instituída com o objetivo de incrementar as pesquisas no campo do Poder Aeroespacial, que é amplo e multifacetado. A grosso modo, enquanto o complexo universitário da Aeronáutica, localizado em São José dos Campos, está mais voltado para as áreas aeroespacial e tecnológica da defesa aérea nacional, a UNIFA se dedica ao ensino, à pesquisa e à difusão de conhecimentos que atendam a outras áreas de interesse da Força Aérea, tais como: medicina aeroespacial, estratégia, logística, educação, direito, aptidão física do aeronavegante, história, dentre outras. A maior dificuldade encontrada para o desempenho da sua missão, desde a sua fundação, tem sido a falta de um corpo docente qualificado nessas áreas. Além do penoso trabalho de se encontrarem experts nesses assuntos, sob a ótica militar, no meio civil, existe a de se realizarem concursos públicos para professores de nível superior.

Quanto à sua localização, a UNIFA fica na cidade do Rio de Janeiro, no bairro Campo dos Afonsos. Muitos não sabem, mas, este é um sítio histórico de extremo valor para a história do Brasil, da aviação, do Rio de Janeiro, do Exército Brasileiro, da Força Aérea Brasileira, da educação brasileira, dentre outros campos da História. ${ }^{2}$

\footnotetext{
${ }^{1}$ No dia 26 de setembro de 1983 , por meio do Decreto $n^{\circ} .88 .749$.

${ }^{2}$ Para mais detalhes, ver Cardoso (2012).
} 
Figura 1- Entrada da UNIFA

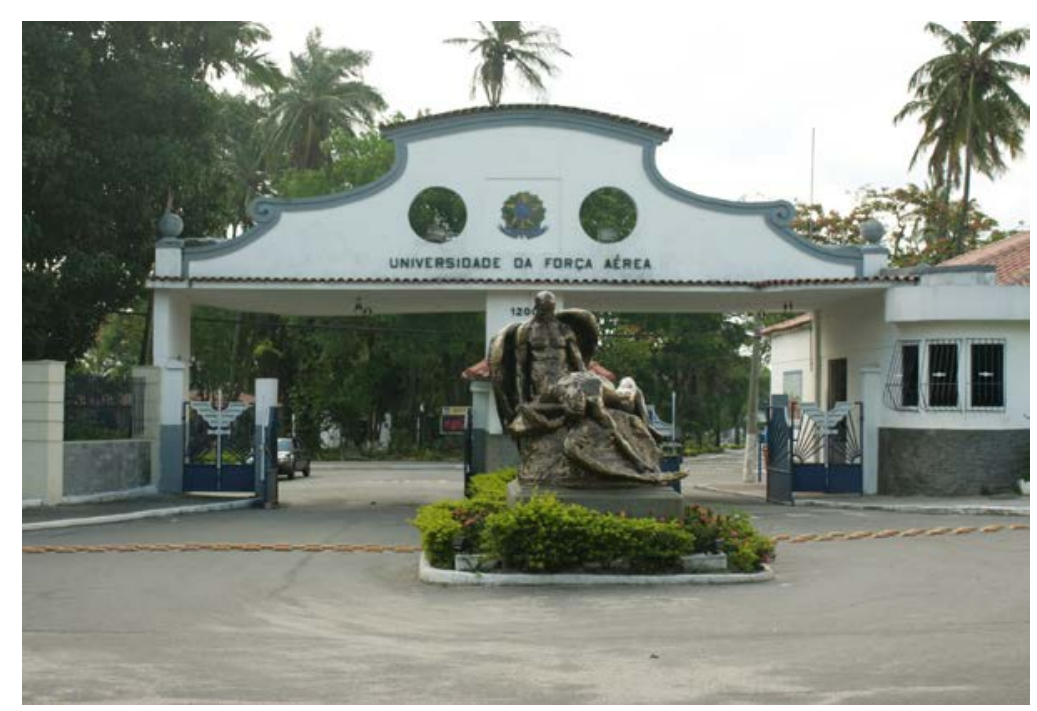

Fonte: CME/UNIFA.

O Centro de Memória do Ensino Militar (CME), situado na UNIFA, foi criado em 29 de dezembro de 2010, por meio da Portaria nº. 127. Ele ocupa uma antiga Sala de Esgrima da extinta Escola de Aeronáutica, que funcionou ali de 1941 até 1972.

$\mathrm{Na}$ sua logomarca, podemos observar o olho de uma coruja, símbolo da Pedagogia ${ }^{3}$, ciência da Educação e, no seu interior, o túnel do tempo.

Figura 2- Logomarca do CME/UNIFA

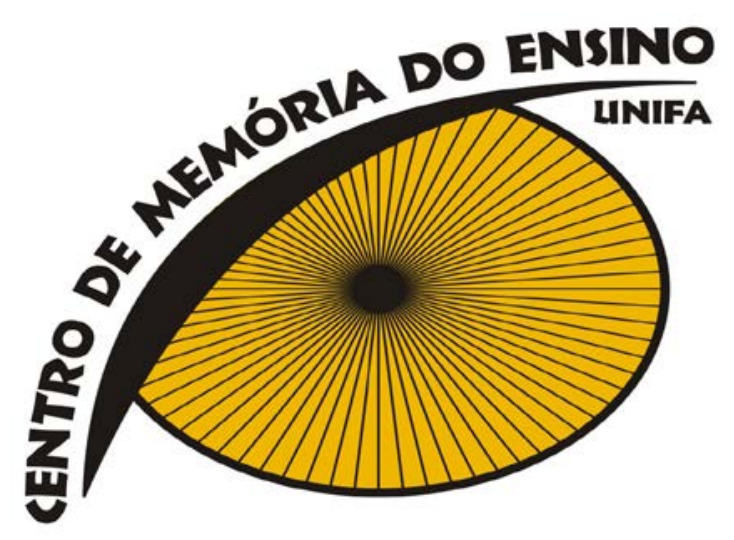

Fonte: CME/UNIFA.

\footnotetext{
${ }^{3}$ A coruja simboliza a sabedoria, a reflexão, o conhecimento. Assim, além da Pedagogia, ela é empregada como símbolo da Filosofia e das Letras.
} 
A ideia da criação do CME/UNIFA surgiu quando da realização de um curso de doutorado em Educação, na Universidade de São Paulo (USP), no ano de 2004, quando tive contato com o Centro de Memória da Educação desta Instituição.

Como orientanda da Prof. ${ }^{a}$ Dr. ${ }^{a}$ Diana Gonçalves Vidal, especialista no assunto, pude observar o trabalho realizado naquele Centro. Também tive a oportunidade de participar da organização do I Encontro de Arquivos Escolares e Museus Escolares, ocorrido em 2005, na USP, efetuada pelo grupo de pesquisa da referida professora, denominado Núcleo Interdisciplinar de Estudos e Pesquisas em História da Educação (NIEPHE).

Durante a realização de um doutoramento “sandwich" na Universidade de Coimbra, em 2005/2006, financiado pela Coordenação de Aperfeiçoamento de Pessoal de Nível Superior (CAPES), aproveitei a oportunidade para investigar a existência de arquivos, bibliotecas, museus e centros de documentação, especializados no campo da educação militar. Todavia, nada encontrei, naquela época, sobre o assunto, nem na Europa e nem nas Américas.

Algum tempo depois de retornar da viagem a Portugal, passei a ocupar uma sala destinada à guarda de material antigo da UNIFA, onde estavam depositados documentos que registravam a história do ensino na Aeronáutica desde a década de 1970. Isto porque grande parte dos documentos do órgão central de ensino da Força - inicialmente denominado Diretoria de Ensino (DIRENS) e, posteriormente, Departamento de Ensino (DEPENS) - foi depositada na Universidade quando da transferência deste (agora) "grande Comando" 4 para Brasília.

Convicta da importância do assunto para a melhoria da qualidade do ensino na Aeronáutica, elaborei o projeto de implantação do CME/UNIFA, cuja finalidade seria a preservação do que já foi realizado na área do ensino por militares e civis daquela Instituição, de modo a aproveitar esses saberes, perdidos no tempo, para a compreensão e a melhoria da missão educacional militar presente.

\footnotetext{
${ }^{4}$ Comando de Tenente Brigadeiro, último posto da Aeronáutica, em tempo de paz.
} 
O projeto foi aprovado, em 2008, pelo então Major Brigadeiro do Ar Louis Jackson Josuá Costa, na época, Comandante e Reitor da UNIFA ${ }^{5}$. No ano de 2010, no Comando do Maj. Brig. do Ar Robinson Velloso Filho, o CME foi criado oficialmente e ganhou o seu espaço físico - a antiga Sala de Esgrima.

O Centro surgiu, inicialmente, com a finalidade de reunir, recuperar, analisar e divulgar acervos histórico-educacionais da Aeronáutica. Todavia, como muitos dos documentos relevantes sobre a história dessa Instituição, bem como do Exército e da Marinha do Brasil, estivessem sendo descartados, além daqueles relacionados ao ensino militar nessas três Forças, o Centro tornou-se um lugar de preservação de fontes documentais relativas à história militar e à história do ensino militar, em geral.

O trabalho de "salvamento" de documentos foi o primeiro a ser realizado", já em 2008. Escolhemos iniciar essa atividade no depósito geral de lixo da Instituição, localizado nos fundos do terreno da Universidade. Lá, foram encontrados, em péssimo estado de conservação, por exemplo, documentos da década de 1910, época da fundação do Aeroclube Brasileiro, que deu início às atividades de voo naquele sítio histórico, transformando-o no Campo dos Afonsos. Também, material instrucional da antiga Escola de Aeronáutica, que precedeu a atual Academia da Força Aérea, além de documentação sobre as Escolas que se encontram subordinadas ao Comando da Universidade.

Paralelamente às atividades no "lixão", foram realizadas visitas às Escolas do campus: Escola de Comando e Estado-Maior da Aeronáutica (ECEMAR), Escola de Aperfeiçoamento de Oficiais da Aeronáutica (EAOAR) e Centro de Instrução Especializada da Aeronáutica (CIEAR), para saber se gostariam de doar algum material para o CME. Essas Organizações de Ensino cederam ao Centro de Memória uma grande quantidade de documentos impressos, fotográficos, audiovisuais, além de móveis e recursos instrucionais antigos que ocupavam espaços necessários às demandas educacionais daquele momento.

\footnotetext{
${ }^{5} \mathrm{Na}$ UNIFA, o Comandante acumula as funções de Reitor da Universidade.

${ }^{6}$ Aliás, ele continua até hoje.
} 
A Comissão de Desportos da Aeronáutica (CDA), que também ocupa o campus da Universidade, cedeu um material valioso sobre a história do ensino da Educação Física na Aeronáutica.

O próximo passo foi, então, divulgar externamente as atividades do CME/UNIFA, na esperança de receber doações, também, de particulares. Solicitamos o apoio do Centro de Comunicação Social da Aeronáutica (CECOMSAER), no sentido de publicar no contracheque de militares e civis da Força uma "propaganda" do nosso trabalho, esclarecendo o seu objetivo e a necessidade que tínhamos de receber material pedagógico que pudesse ajudar a contar a história do ensino na Aeronáutica. Infelizmente, foram poucos os documentos recebidos; em compensação, muitas as denúncias de descarte de material histórico educacional.

Nessa época, eu trabalhava sozinha no Centro e conseguia, uma vez ou outra, um ou dois Soldados ${ }^{7}$ para me ajudar no "salvamento" do material, que passou a ser depositado na sede do CME/UNIFA. Recordo-me de que, quando não era possível conseguir uma viatura militar para transportar os livros, fazia uso de um antigo táxi do meu pai, já falecido, uma Santana Quantum, para transportar o material para o Centro. Dirigindo aquele carro amarelo, ninguém acreditava que eu era uma Tenente Coronel! Mas, apesar de todas as dificuldades encontradas, tudo aquilo me dava um imenso prazer e eu acabava rindo de mim mesma!

Em visita ao Instituto de Geografia e História Militar do Brasil (IGHMB), tomei conhecimento de que documentos escolares estavam prestes a serem descartados em algumas instituições escolares do Exército, por serem considerados antigos. Também, que a Biblioteca do Exército estava abarrotada de livros, no limite de sua capacidade física.

Mais tarde, em 2012, fiz uma visita à Academia Militar das Agulhas Negras (AMAN), por ocasião do I Encontro de Historiadores Militares, e tive a oportunidade de conversar com alguns membros da administração da Academia sobre a importância da preservação daquele patrimônio escolar, até mesmo para a própria Instituição.

\footnotetext{
${ }^{7}$ Hoje, um Soldado vale ouro!
} 
Como bem lembra Rosa Fátima de Souza:

[...], a conservação do patrimônio escolar deveria servir, em primeiro lugar, às próprias escolas e à comunidade escolar para reconhecer o significado sociocultural da instituição, como memória afetiva da experiência escolar, mas, principalmente, como ferramenta de reflexão sobre o significado da escola como instituição ao longo do tempo e os sentidos de sua atuação no presente. (p. 214)

Quanto à Biblioteca do Exército, esta doou ao CME/UNIFA verdadeiros tesouros, não só para a história da educação militar, mas, também, para a história militar e para a história do Brasil. O problema é que alguns livros estão em péssimo estado de conservação.

Também a Biblioteca da Marinha colaborou com o acervo do Centro de Memória, permitindo que visitássemos o seu depósito de livros e selecionássemos os de interesse para o campo de pesquisa do CME/UNIFA. ${ }^{8}$

Entretanto, ainda há muito material para ser livrado da ruína na própria Aeronáutica, no Exército e na Marinha, e isso nos angustia muito. Apesar de as Forças Armadas prezarem pelos seus patrimônios históricos há muito tempo, há um completo desconhecimento sobre a importância da preservação do patrimônio escolar.

Sabemos que esse é um problema geral, uma vez que tal assunto tem sido tratado muito recentemente pelos pesquisadores da área da História da Educação, principalmente no Brasil, como atestam Maurilane de Souza Biccas e Maria Ângela Borges Salvadori:

O debate sobre a importância desses centros se constitui em algo recente no campo da história da educação. Simultaneamente, contudo, trata-se de questão urgente, pois a inexistência de políticas públicas voltadas para a preservação de acervos documentais dificulta 0 desenvolvimento de pesquisas nesta área específica. (p. 147)

Para Nádia Gaiofatto Gonçalves (2006), a discussão sobre o tema se intensificou, no País, mais precisamente, a partir da década de 1990, sob a influência das ideias do expoente da História Cultural, Roger Chartier:

\footnotetext{
${ }^{8}$ A essas duas Bibliotecas, o nosso imenso agradecimento.
} 
O debate acerca dos arquivos escolares tem se tornado mais freqüente a partir da década de 1990, no Brasil, aliado às questões colocadas pela História Cultural, cujo interesse e uso de referenciais têm sido crescentes, na História da Educação. [...]. Nesta perspectiva, a definição de Chartier a respeito da História Cultural, como 'uma história dos objetos na sua materialidade, uma história das práticas nas suas diferenças e uma história das configurações, dos dispositivos nas suas variações' (1988, p. 45) é bastante sugestiva em possibilidades para o estudo das Instituições Educacionais. (ANAIS DO IV CONGRESSO ...)

Todavia, como salientaram Biccas e Salvadori (2005), é necessário traçar uma política nacional de preservação do patrimônio escolar urgentemente, pois, arquivos de fundamental importância para a compreensão da história da educação no nosso País podem estar sendo destruídos neste momento.

Quanto ao uso das novas tecnologias para a preservação de documentos, a pesquisadora Diana Gonçalves Vidal (2000) faz o seguinte alerta:

[...] para a pesquisa (e escrita) em história e em história da educação, toda ela produzida a partir do diálogo entre o historiador, seus pares e a fonte, a guarda de documentos antigos (e presentes) é uma imposição. $[\ldots]$.

Os perigos da nova tecnologia, seus desafios, estão relacionados à sua rápida obsolescência. Um livro abre-se sempre à leitura. [...]. No entanto, seu fechamento nunca é tão completo quanto o disquete ou CD-ROM, cuja leitura deve ser sempre mediatizada por uma máquina. (p. 34-35)

Concordamos, portanto, com Souza (2013, p.214), no sentido de que é necessário elaborar uma política de preservação do patrimônio escolar. Neste sentido, "cabe ao Estado definir diretrizes e normas para proteger, valorizar e difundir o patrimônio escolar [...]. Além disso, é preciso ter em vista a colaboração entre os entes federados na gestão pública desse patrimônio, ou seja, os governos estaduais e municipais."

Esse discurso pode parecer contaminado pelo atual culto (quase planetário) ao patrimônio cultural, em que "A patrimonialização tomou uma amplitude tal que corre-se o risco de considerar-se 'tudo patrimônio' ". (HARTOG, 2006) ${ }^{9}$. Pode ser... Mas, não

\footnotetext{
${ }^{9}$ A patrimonialização em excesso seria um indício do nosso mau relacionamento com o tempo presente. Uma vez que a identidade do Homem está em crise, perdida, em busca de si mesma, ele tende a preservar tudo o que diz respeito, principalmente ao seu passado recente, a fim de salvaguardar a sua identidade atual que estaria sendo apagada. (HARTOG, 2006).
} 
podemos negar a importância dos acervos documentais para a pesquisa na área da História da Educação. Clarice Nunes e Marta Carvalho já abordaram esse assunto, em 1992, quando da realização da $15^{a}$ Reunião Anual da Associação Nacional de PósGraduação e Pesquisa em Educação (ANPEd):

[...] a compreensão crítica da trajetória da educação no nosso país fica comprometida não só pelo desconhecimento dos acervos existentes nos arquivos, mas também pela ausência de uso de acervos organizados e disponíveis para a pesquisa [...]. Por essas razões, trabalhos que priorizem a localização de acervos, e a discussão em torno de levantamentos já existentes, são fundamentais para a renovação da prática da pesquisa histórica no campo da educação [...] Mapear fontes é, portanto, preparar o terreno para uma crítica empírica vigorosa que constitua novos problemas, novos objetos e novas abordagens. (apud GONÇALVES, 2006)

Cabe ressaltar que, por conta dessa nostalgia, o CME/UNIFA não pretende tornarse um espaço abarrotado de informações sobre o ensino militar ${ }^{10}$. Seu intuito é, através da seleção de documentos, subsidiar o trabalho do pesquisador na busca de respostas para os seus problemas de pesquisa, tornando o seu acervo documental, bem como os das instituições militares de ensino parceiras, disponível para consulta.

Assim, da mesma forma que existe a necessidade da elaboração de uma política de preservação do patrimônio escolar, também é indispensável a elaboração de uma política de descarte de documentos escolares, como mencionado por Vidal (2000), para que não corramos o risco de transformar tudo em patrimônio.

Para aqueles que buscam no passado um refúgio para o tempo presente, é bom lembrar que, às vezes, o esforço de construção da memória, longe de tornar o passado melhor do que o presente,

devolve a vida àquelas possibilidades que, uma vez derrotadas, sofreram um processo corrosivo de esquecimento. Neste sentido, lembrar é também refazer um trajeto e devolver voz a experiências negligenciadas. A organização de acervos de memória em geral, e da história da educação em particular, pode, assim, nos aproximar mais efetivamente do sentido que a educação teve para professores e alunos em diferentes momentos e lugares, sentido que tantas vezes sucumbiu diante da aridez

\footnotetext{
${ }^{10}$ O CME tem como um dos seus objetivos assessorar as organizações militares de ensino na organização de seus próprios centros de memória, como veremos mais adiante, pois a nossa opinião é a mesma de Souza. (2013, p. 214).
} 
Quanto à natureza do CME/UNIFA, pode-se afirmar que ele é um centro de documentação, especializado em história da educação militar. Ele possui documentos classificados como de arquivo, de biblioteca e museológico.

Para Viviane Tessitore (2003, p.13), o centro de documentação representa uma mistura de arquivo, biblioteca e museu, sem se identificar com nenhuma dessas entidades. Aliás, “por ser uma entidade 'mista', [...] não conta com uma teoria e metodologia específicas para o tratamento do acervo, [...]."

O centro de documentação, além de reunir documentos sobre uma área específica da atividade humana, tem como características:

- possuir documentos arquivísticos, bibliográficos e/ou museológicos, constituindo conjuntos orgânicos (fundos de arquivo) ou reunidos artificialmente, sob a forma de coleções, em torno de seu conteúdo;

- ser um órgão colecionador e/ou referenciador;

- ter acervo constituído por documentos únicos ou múltiplos, produzidos por diversas fontes geradoras;

- possuir como finalidade o oferecimento da informação cultural, científica ou social especializada;

- realizar o processamento técnico do seu acervo, segundo a natureza do material que custodia. (Ibid., p. 14)

De acordo com as propostas de Regulamento e de Regimento Interno da UNIFA, encaminhadas ao DEPENS, no ano de 2013, para aprovação, são atribuições do CME:

I - desenvolver atividades para a preservação, a organização, a guarda e

a divulgação de acervos documentais, bibliográficos, materiais, imagéticos e audiovisuais significativos para o resgate da memória e da história militar, em especial, do seu ensino;

II - promover e integrar estudos e pesquisas interdisciplinares voltados para a reconstrução da memória e da história militar, principalmente do seu ensino;

III - interagir com instituições congêneres e pesquisadores, em prol do desenvolvimento de estudos e de pesquisas acadêmicas afetos à área da memória e da história militar, principalmente do seu ensino; 
IV - desenvolver atividades relativas à divulgação da memória e da história militar, principalmente do seu ensino;

V - organizar e promover eventos de ordem acadêmica (simpósios, seminários, conferências, debates, exposições, cursos, oficinas, treinamentos, estágios, entre outros) voltados para a preservação da memória e da história militar, principalmente do seu ensino, nas áreas de Arquivologia, Biblioteconomia, Restauração, Iconografia, História Oral, dentre outras que se ocupam da preservação do patrimônio cultural;

$\mathrm{VI}$ - prestar assessoria a projetos ligados à memória e à história militar, principalmente ao seu ensino;

VII - colaborar com as Organizações de Ensino na organização de espaços históricos dedicados à memória e à história da educação;

VIII - colaborar na criação e na execução de cursos de pós-graduação nas áreas de sua especialização, propostos no âmbito da UNIFA;

IX - colaborar com os projetos de pesquisa e de extensão promovidos pelos setores competentes da UNIFA, nas áreas de sua especialização;

$X$ - colaborar com instituições educacionais e/ou culturais internas e externas, sendo necessária, neste último caso, a autorização da Reitoria da UNIFA; e

XI - promover atividades relacionadas à educação patrimonial no Comando da Aeronáutica.

A fim de assegurar a contratação de pessoal especializado, foram criadas, no Regimento Interno, as seguintes seções: a) Seção de Pesquisa História, que deverá ser chefiada por um docente pesquisador da área; b) Seção Técnico-Científica, a ser dirigida por uma arquivista, bibliotecária ou museóloga; c) Seção de Divulgação Científica e Aperfeiçoamento Profissional, chefiada por funcionário com curso superior em uma das seguintes áreas: cultural, educacional ou histórica; e d) Secretaria.

É importante destacar que o CME/UNIFA deverá possuir um Conselho Científico, que será o seu órgão deliberativo superior.

Quanto aos recursos, no ano de 2011, foi lembrado aos superiores hierárquicos que o Campo dos Afonsos faria cem anos, em 2012, o que ocasionou a liberação de verba do 
Comando da Aeronáutica para a realização de um seminário, uma exposição fotográfica, um livro histórico e um documentário, tudo fruto das pesquisas realizadas pelo Núcleo Interdisciplinar de Estudos e Pesquisas em História da Educação Militar (NIEPHEM), grupo de pesquisa do CME/UNIFA. Todavia, a verba utilizada para compra da maior parte do material necessário às atividades do Centro (luvas, máscaras, jalecos, toucas, extensões elétricas, remédio para matar cupins, vassoura, ...) saiu do bolso da pesquisadora que escreve este artigo.

No ano de 2013, a UNIFA passou a ser administrada por outro oficial general que, infelizmente, não compreendeu a finalidade do nosso trabalho. Entretanto, fomos salvos da destruição completa pelo Tenente Brigadeiro do Ar, Dirceu Tondolo Nôro, atual Diretor do Departamento de Ensino da Aeronáutica, que, conhecendo o CME, liberou uma verba de $\mathrm{R} \$ \mathbf{9 4 . 6 0 8 , 1 8}$ para a compra de material permanente e de consumo para o Centro ${ }^{11}$. Todavia, a verba chegou à Universidade em julho desse mesmo ano, mas, ainda não tinha chegado ao CME no mês de abril de 2014, quando fui afastada da sua Chefia... ${ }^{12}$

Somente há pouco tempo, a UNIFA foi cadastrada na CAPES como Universidade e o grupo de pesquisa do CME, o NIEPHEM, só pôde entrar para o Diretório de Grupos de Pesquisa do CNPq, em $2013^{13}$. Assim, esperamos, a partir de agora, poder concorrer aos editais das agências de fomento à pesquisa do País, a fim de conseguir recursos para as nossas atividades científicas.

No que se refere ao acervo, como mencionado anteriormente, os documentos sob a guarda do CME/UNIFA são oriundos das três Forças Armadas brasileiras e têm sido

\footnotetext{
${ }^{11}$ Em 2012, o Ten. Brig. Nôro, na época Maj. Brig. e Vice-Diretor do DEPENS, resolveu entrar no CME, por acaso, quando de uma visita oficial à UNIFA. Naquela época, as pessoas tinham muito receio de entrar no Centro porque havia muita poeira; por isso, ao ver aquele Brigadeiro, levei um susto! Ele estava sozinho e tivemos a oportunidade de lhe oferecer uma palestra informal sobre os objetivos do Centro, suas atividades e a importância da preservação do patrimônio cultural para a formação da identidade militar. Considerando o tratamento grosseiro que alguns militares me dispensaram após o ocorrido, acreditamos que, graças a essa visita, esse oficial general impediu que o Rancho dos Oficiais, prédio histórico localizado no Campo dos Afonsos, fosse completamente destruído.

${ }^{12}$ Atualmente, o CME/UNIFA está sendo chefiado por um Coronel Aviador que não possui curso de pósgraduação lato sensu ou stricto sensu, reconhecido pela CAPES, e nunca trabalhou como profissional da área educacional.

${ }^{13}$ Até então, permanecemos no Núcleo Interdisciplinar de Pesquisa em História da Educação e Infância (NIPHEI), coordenado pela Profa. Dr ${ }^{a}$. Sônia Câmara Rangel e pelo Prof. Dr. Jorge Antônio Rangel (Fidel), ambos da UERJ. A eles, o meu eterno agradecimento. Também agradeço ao Prof. Ms. José Carlos Xavier Bonfim, pertencente a esse grupo de pesquisa, pela colaboração prestada ao CME/UNIFA.
} 
recolhidos desde 2008. O acervo abrange um período extenso da história militar do Brasil e do seu ensino, que remonta à época colonial.

Esses fundos compõem-se de: atas, livros raros, apostilas, periódicos, mapas, planos de aula, legislações sobre o ensino militar, equipamentos de auxílio à instrução, mobiliário escolar, fitas, filmes, fotografias, pinturas, coleções científicas, coleções didáticas, dentre outros documentos. Todavia, o acervo ainda está completamente desorganizado e muitos documentos, em péssimo estado de conservação.

Figura 3- O CME/UNIFA em 2010

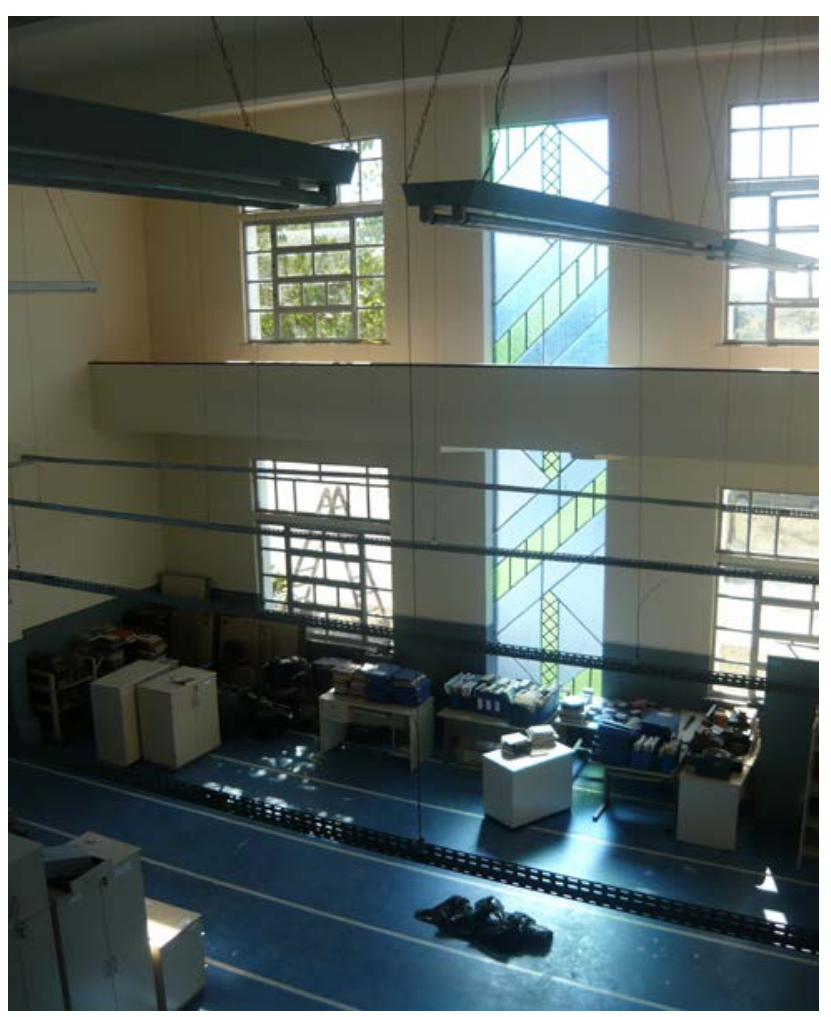

Fonte: CME/UNIFA. 
Figura 4- O CME/UNIFA em 2012

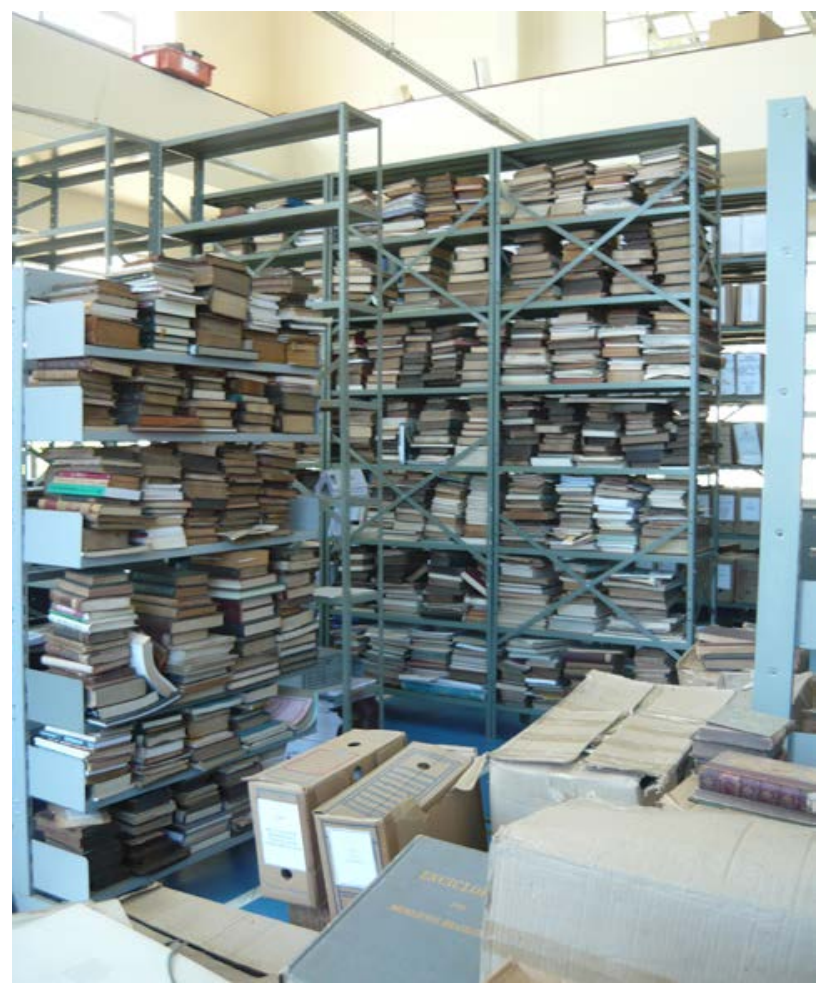

Fonte: CME/UNIFA.

Figura 5- O CME/UNIFA em 2013

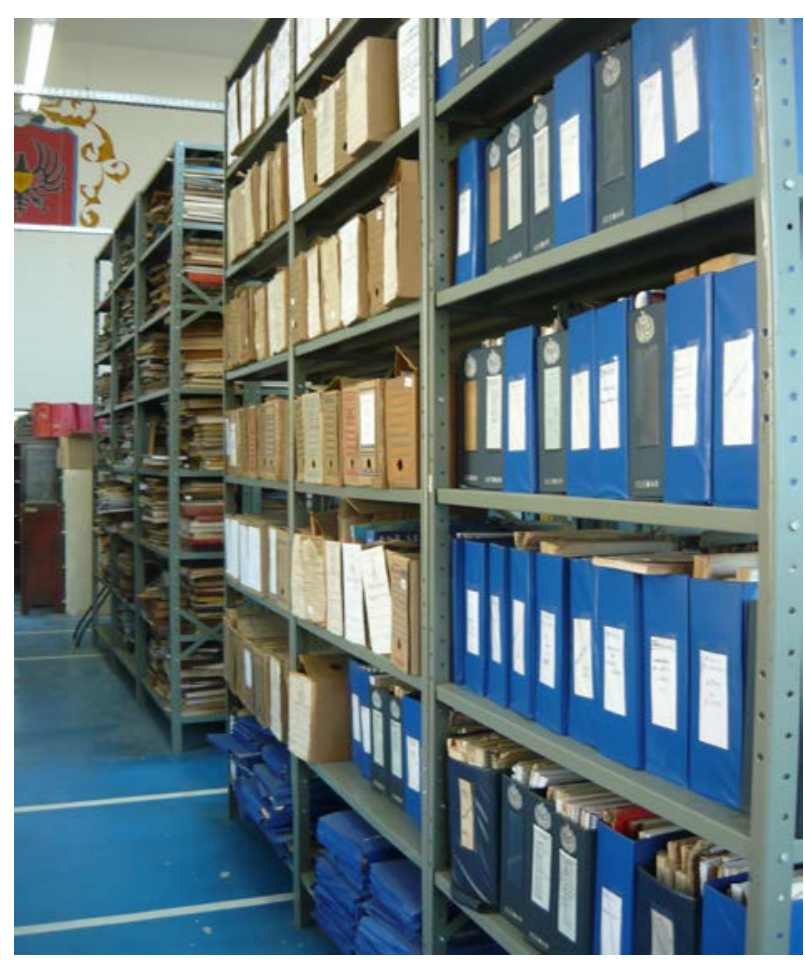

Fonte: CME/UNIFA. 
Acreditamos que esses documentos, oficiais ou não, podem revelar muito do cotidiano das instituições escolares militares. Concordamos com Diana Gonçalves Vidal (2005, p. 19) quando destaca a importância do arquivo para a compreensão de uma determinada instituição escolar, de sua existência e de sua relação com o seu entorno. Os arquivos não seriam somente lugares de memória, locais de guarda dos acervos, mas, também, "constantemente abertos a novas leituras acerca do passado e do presente."

[...] integrado à vida da escola, o arquivo pode fornecer-lhe elementos para a reflexão sobre o passado da instituição, das pessoas que a frequentaram ou frequentam, das práticas que nela se produziram e, mesmo, sobre as relações que estabeleceu e estabelece com seu entorno (a cidade e a região na qual se insere)." (Ibid., p. 24)

Uma vez que os fundos arquivísticos estão sendo organizados por instituições de ensino militar (AFA, EPCAR, EEAer, ...), poderá ser revelada a existência, não de uma cultura escolar, mas de várias culturas escolares, uma vez que não há duas instituições de ensino iguais: "No hay dos escuelas, colegios, institutos de enseñanza secundaria, universidades o faculdades exactamente iguales, aunque puedan establecerse similitudes entre ellas." (VIÑAO FRAGO, 2001, p. 33).

Exemplos de documentos existentes no CME/UNIFA:

Figura 6- Livro de 1866

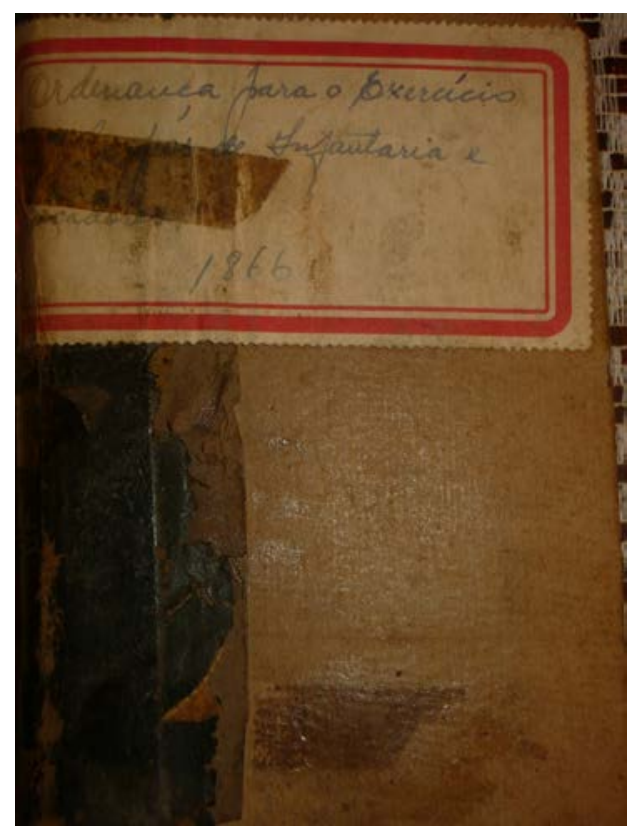

Fonte: CME/UNIFA. 
Figura 7- Livro de 1866

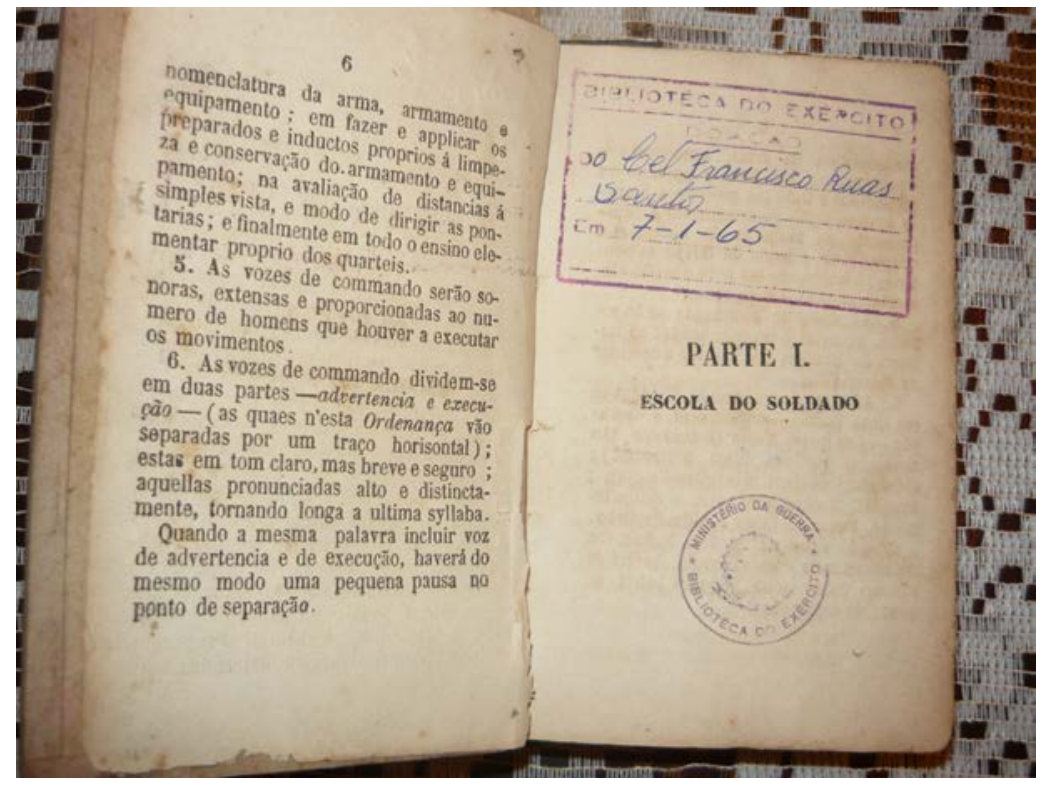

Fonte: CME/UNIFA.

Figura 8- Apostila do Instituto Tecnológico da Aeronáutica de 1969

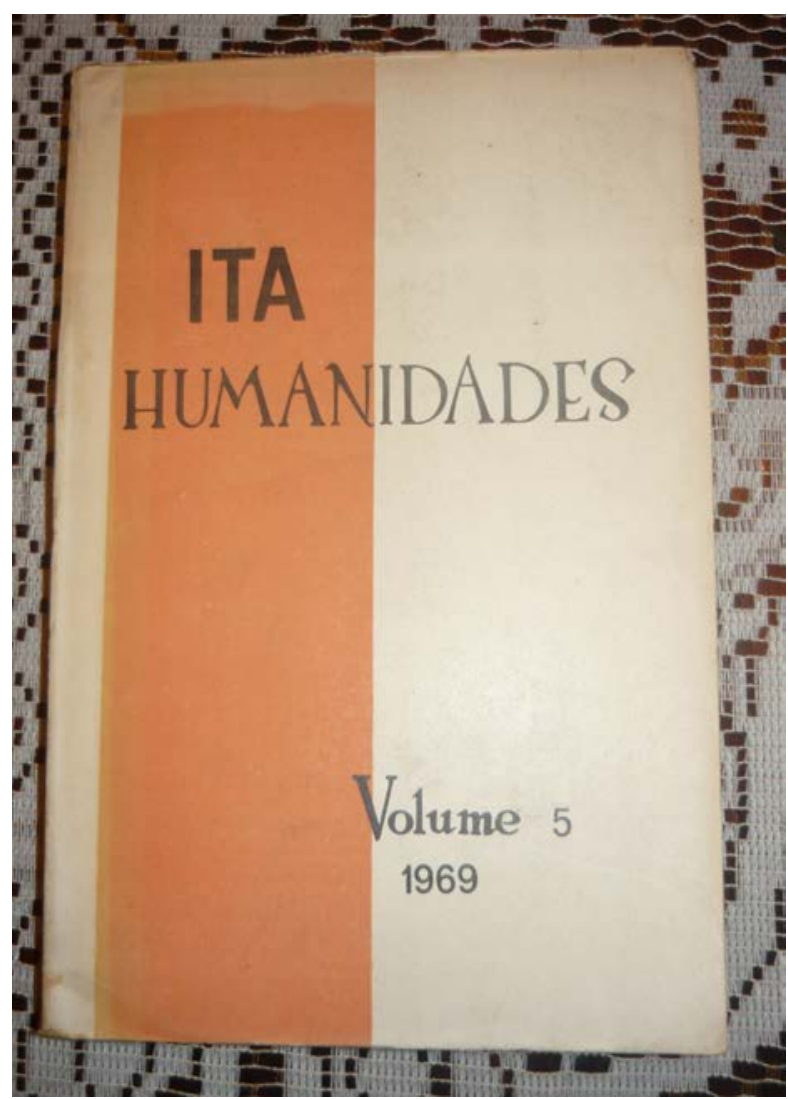

Fonte: CME/UNIFA. 
As figuras 5 e 6 retratam o mesmo documento. É um livro do século XIX (1866) que ensina aos militares como deve funcionar uma Escola para Soldados. O seu conteúdo abrange desde a sua estrutura até os conteúdos que devem ser abordados nas aulas, incluindo a metodologia de ensino.

No que se refere ao acervo fotográfico, podemos dizer que, a partir de um levantamento preliminar, identificamos, por exemplo, imagens que retratam alunos em diferentes situações de instrução.

Há também filmes de rolo que reproduzem acontecimentos escolares; porém, estão em mau estado de conservação.

Figura 9- Laboratório de Química da Escola de Aviação Militar (1930)

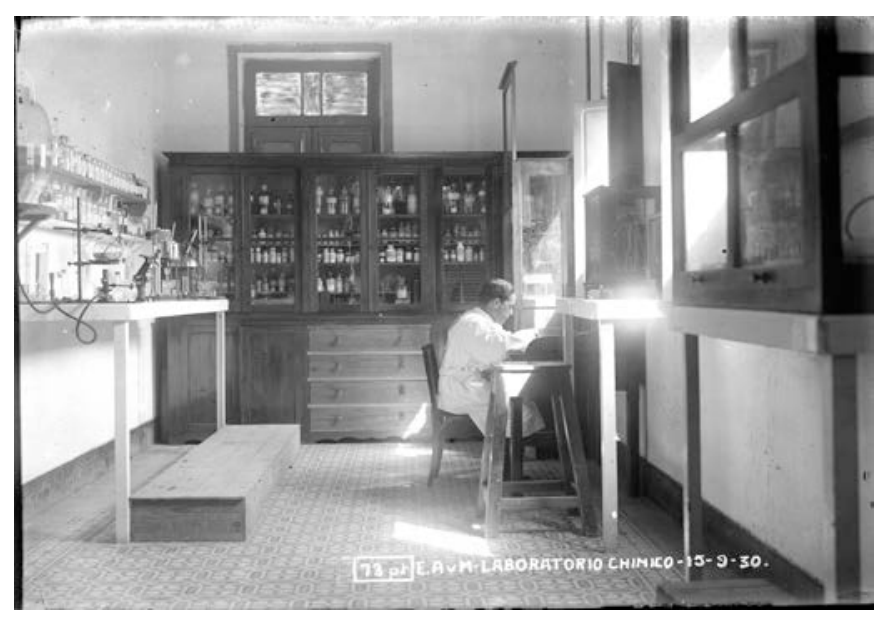

Fonte: CME/UNIFA.

Figura 10- Aula de Instrumentos na Escola de Aviação Militar

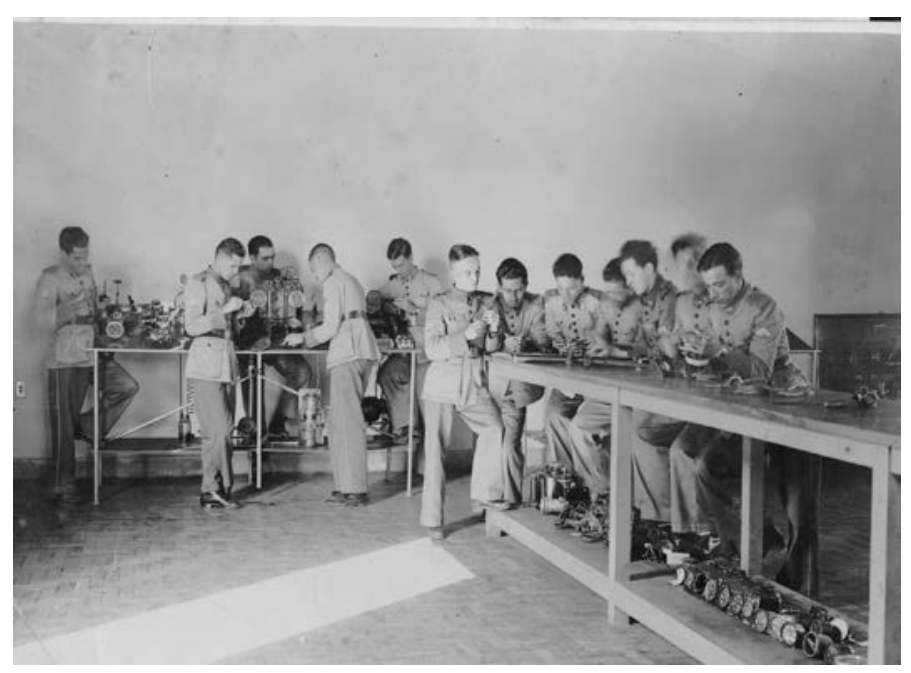

Fonte: CME/UNIFA. 
Figura 11- Aula de Mecânica na Escola de Aviação Militar

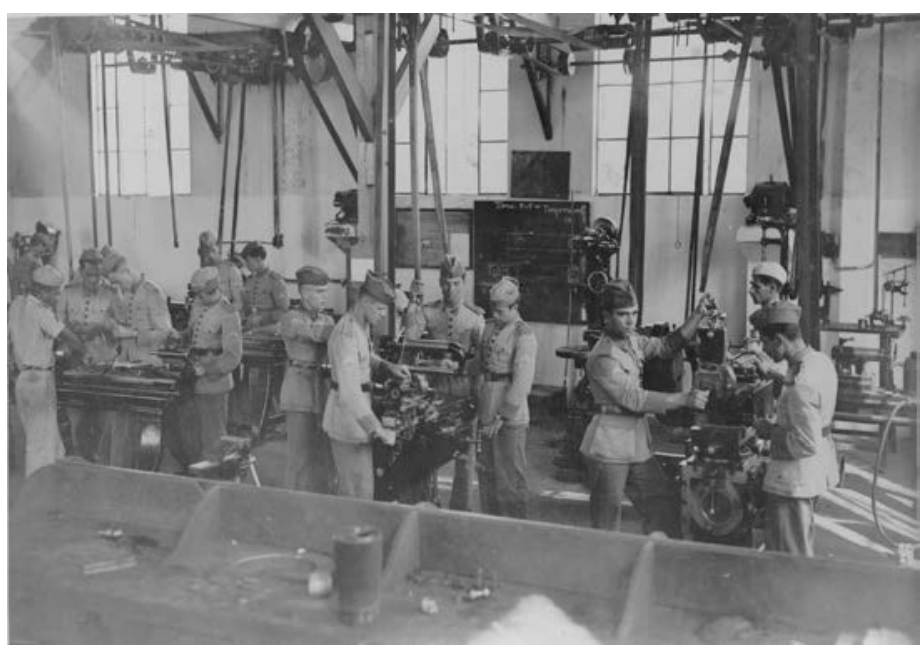

Fonte: CME/UNIFA.

Figura 12- Normalistas visitando a Escola de Aeronáutica

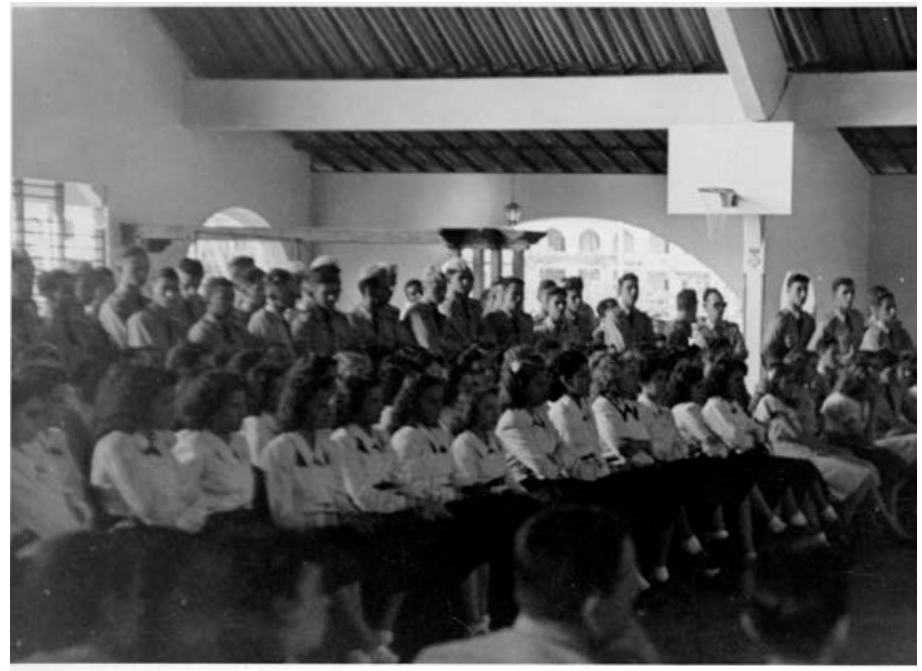

Fonte: CME/UNIFA.

$\mathrm{Na}$ busca de conhecimentos para organizar o CME/UNIFA, principalmente o seu acervo, iniciamos o pós-doutorado da Faculdade de Educação da Universidade de São Paulo (FEUSP), cujo Corpo Docente já acumulou uma grande experiência no assunto. $O$ estágio está sendo supervisionado pela Profa ${ }^{a}$ Dra . Diana Gonçalves Vidal, que realizou uma grande quantidade de estudos acerca da cultura escolar, da sua preservação e organização, bem como atuou como coordenadora do Centro de Memória da FEUSP.

Assim, na organização do acervo do CME/UNIFA pretende-se, no período de um ano, classificar, selecionar e identificar todos os documentos; elaborar um plano de 
arranjo do acervo; viabilizar o trabalho de higienização, acondicionamento e tratamento adequado aos documentos; e digitalizar esse material, visando a constituir um banco de dados sobre o conjunto da documentação manuseada, a fim de disponibilizar para consulta todos os documentos registrados (sem nos livrar dos papéis...).

Em função das atribuições do CME/UNIFA e do planejamento para a comemoração do centenário do Campo dos Afonsos, ocorrido no ano passado, foi criado o primeiro grupo de pesquisa histórica da Aeronáutica, no ano de 2011: o Núcleo Interdisciplinar de Estudos e Pesquisas em História da Educação Militar (NIEPHEM), citado anteriormente. Este grupo, por mim coordenado, é constituído por 11 pesquisadores, militares e civis, sendo 1 doutor, 2 doutorandos, 2 mestres e 1 aluna do Curso de Graduação em História da UFRJ.

Figura 13- Alguns membros do NIEPHEM, em 2012

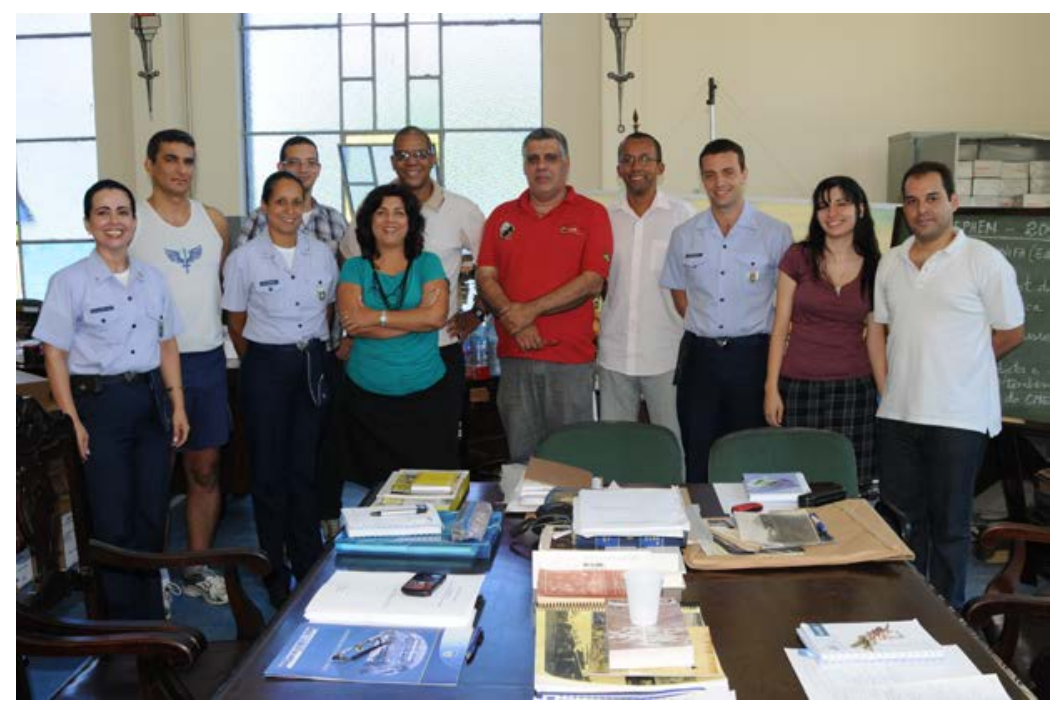

Fonte: CME/UNIFA.

O grupo compõe-se de profissionais de várias áreas, a saber: educação, história, biblioteconomia, arquivologia, museologia e comunicação visual.

Durante dois anos, várias pesquisas foram realizadas, individualmente e em grupo, pelos integrantes do NIEPHEM, o que resultou na publicação do livro Campo dos Afonsos: 100 anos de história da aviação brasileira, na exposição fotográfica Campo dos Afonsos: 
passado e presente (também transformada em catálogo ${ }^{14}$ ) e no documentário Paisagem e espaço: a história do Campo dos Afonsos de 1912 a 2012. Os temas abordados nessas pesquisas foram os seguintes:

- A origem dos Afonsos;

- Os primórdios da aviação no Brasil (1912-1918);

- A consolidação da aviação militar no Campo dos Afonsos (1918-1931);

- A conturbada década de 1930 e a modernização da Escola de Aviação Militar, localizada no Campo dos Afonsos;

- A divulgação da aviação militar brasileira na imprensa (1910-1914);

- A Escola de Aeronáutica (1941-1973);

- O Campo dos Afonsos: de 1973 até 1982; e

- A criação da Universidade da Força Aérea.

O trabalho de campo foi realizado no Arquivo Nacional (AN), na Biblioteca Nacional (BN), no Centro de Pesquisa e Documentação de História Contemporânea do Brasil (CPDOC), no Instituto Histórico-Cultural da Aeronáutica (INCAER), no Centro de Documentação da Aeronáutica (CENDOC), no Museu Aeroespacial (MUSAL) e, principalmente, no CME.

Cabe ressaltar que o NIEPHEM-CME/UNIFA também organizou o I Seminário Nacional de História da Aviação Brasileira, realizado nos dias 17, 18 e 19 de julho de 2012, na Universidade da Força Aérea ${ }^{15}$, oportunidade em que foram discutidos vários assuntos, dentre os quais destacamos: Centros de Memória: a luta contra o esquecimento, $O$ ensino formal da História Militar e $O$ ensino não-formal da História Militar. Na ocasião, também foram apresentados vários trabalhos sobre educação patrimonial. ${ }^{16}$

\footnotetext{
${ }^{14}$ Este trabalho contou com a colaboração dos pesquisadores do NIPHEI.

${ }^{15}$ Anais registrados na Biblioteca Nacional sob o $n^{\circ}$. 2238-9407 (ISSN).

${ }^{16} \mathrm{O}$ ícone do CME foi retirado da página da UNIFA, mas o seu site ainda pode ser acessado através do seguinte endereço: https://www.unifa.aer.mil.br/index_cme.php.
} 
Figura 14- Material produzido pelo NIEPHEM, em 2012.

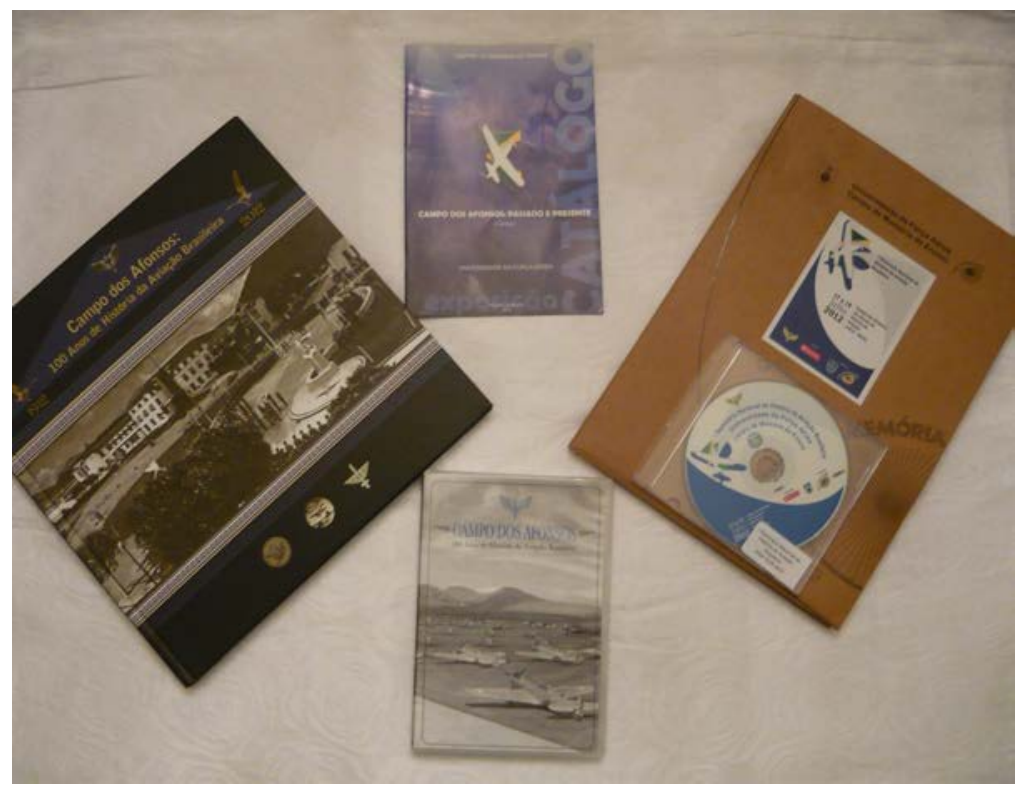

Fonte: CME/UNIFA.

Como visto, há muito trabalho pela frente, o que torna necessária a realização de convênios com outras instituições acadêmicas e/ou culturais, com a finalidade de manter o CME/UNIFA em funcionamento, otimizar seus serviços e, principalmente, democratizar o acesso ao seu acervo documental.

Em 2011, realizou-se parceria técnico-científica, acadêmica e cultural com o Laboratório Interdisciplinar de Estudos e Pesquisas em História da Educação e Infância (LIEPHEI), instituição congênere ao CME, pertencente à Universidade do Estado do Rio de Janeiro (UERJ). Esta parceria com o LIEPHEI, coordenado pela Prof. ${ }^{a}$ Dr. ${ }^{a}$ Sônia Câmara Rangel, auxiliada pelo Prof. Dr. Jorge Antônio Rangel, tem como objetivo estabelecer ações de caráter de ensino, pesquisa, extensão e prestação de serviços em áreas de mútuo interesse, bem como conjugar esforços no sentido de trocar informações acadêmicas e desenvolver projetos, estudos e serviços técnicos, de forma integrada. 0 LIEPHEI/UERJ é constituído por um grupo de pesquisa, cadastrado no CNPq, denominado Núcleo Interdisciplinar de Pesquisa em História da Educação e Infância (NIPHEI). 
Figura 15- O Maj. Brig. do Ar Gracza, Reitor da UNIFA, acompanhado dos alunos e pesquisadores do NIPHEI LIEPHEI/UERJ (2012).

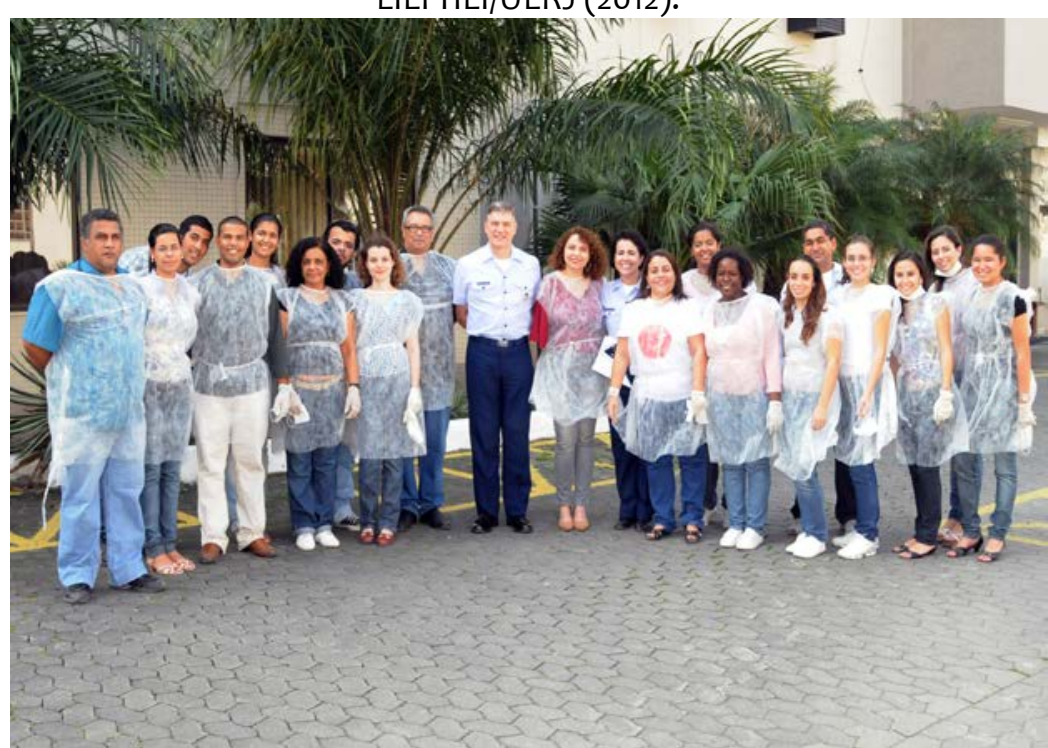

Fonte: CME/UNIFA.

Neste ano de 2014, gostaríamos de continuar a trabalhar em conjunto com o NIPHEI - LIEPHEI/UERJ, bem como dar prosseguimento à realização de parcerias com as seguintes instituições e/ou grupos de pesquisa: a) Biblioteca Nacional, que fez um convite ao CME/UNIFA para participar do Plano Nacional de Obras Raras (PLANOR), com o intuito de auxiliar na recuperação e digitalização das obras raras do Centro; b) Centro de Memória da Faculdade de Educação da Unicamp, representado pelo Prof. Dr. André Luiz Paulilo, com o objetivo de tratar da relação entre os registros civis e militares das práticas de formação e ensino, a fim de compreender as diferentes instâncias de produção, propagação e recepção das ideias e fazeres educativos; e c) Núcleo Interdisciplinar de Estudos e Pesquisas em História da Educação (NIEPHE), coordenado pela Prof. ${ }^{a}$ Dr. ${ }^{a}$ Diana Gonçalves Vidal, da Faculdade de Educação da USP.

Entretanto, não estou mais à frente do Centro... Dependo da autorização de um Chefe que nada entende do que é realizado ali, e o pior, penso que não tem vontade de aprender, mas somente a necessidade de mandar... Além disso, estou certa de que ainda há muito preconceito contra a mulher nas Forças Armadas brasileiras. 


\section{Olhando para o futuro...}

Tínhamos como meta, para 2014 e 2015, organizar e disponibilizar para consulta pública o acervo do CME. Também, através do NIEPHEM: a) organizar o II Seminário Nacional de História da Aviação Brasileira, cujo tema seria A aviação brasileira na I Grande Guerra $^{17}$; b) lançar um livro sobre a Escola Brasileira de Aviação; c) lançar um livro paradidático juvenil sobre a aviação na I G.G., a ser distribuído nas escolas assistenciais da Aeronáutica e nas escolas públicas do entorno da UNIFA; d) organizar uma exposição fotográfica itinerante; e) promover um ciclo de palestras públicas na Universidade sobre os assuntos citados $^{18}$; e f) criar uma revista virtual sobre História Militar e História do Ensino Militar. Tudo financiado pelos Bancos Santander e do Brasil. Entretanto, considerando a situação atual, não sabemos se será possível alcançar esses objetivos...

Apesar de tudo, também queremos acreditar que o Centro continuará colaborando com o Programa de Pós-Graduação da UNIFA nas áreas de sua especialização ${ }^{19}$, no oferecimento de cursos e realização de pesquisas.

Na verdade, o futuro do CME nos parece incerto e isso causa uma tristeza muito grande...

Gostaríamos muito que o Centro pudesse se tornar o guardião do patrimônio escolar militar, principalmente da Aeronáutica, incentivando e colaborando com as instituições militares ${ }^{20}$ de ensino na organização de espaços históricos próprios dedicados à sua memória e à sua história. Quem sabe um dia esse sonho será realizado! No momento, ele parece bem distante...

\footnotetext{
${ }^{17}$ Em 1914, foi criada a primeira escola nacional de aviação militar no Campo dos Afonsos - a Escola Brasileira de Aviação (EBA). Muitos dos seus ex-alunos, que não conseguiram concluir o curso, foram enviados para a Europa, como aviadores, a fim de lutar ao lado dos Aliados durante a I Grande Guerra. Além disso, descobrimos que civis brasileiros também combateram, nessa Guerra, na "arma" da aviação. Quem seriam eles? Como teriam aprendido a voar?

${ }^{18}$ Como observado a partir de 2012, essas palestras, além de informativas, têm promovido a valorização do patrimônio cultural militar por parte do efetivo do Campo dos Afonsos. As pessoas tendem a proteger patrimônios históricos depois de tomar conhecimento do que eles representam para o grupo no qual estão inseridas.

${ }^{19}$ Como a História, a Arquivologia, a Museologia, dentre outras ciências afins.

${ }^{20}$ Existem também instituições civis de ensino, subordinadas a uma administração militar, como é o caso das escolas assistenciais da Aeronáutica. Ex.: Colégio Brigadeiro Newton Braga.
} 


\section{Considerações finais}

Para alguns, a criação de um Centro de Memória da Educação Militar pode parecer sem propósito. Todavia, por meio da realização de pesquisas sobre o tema no mestrado e no doutorado, pude comprovar que há muitos fatos históricos desconhecidos pela sociedade sobre a participação das Forças Armadas na formação de cidadãos brasileiros, no que diz respeito ao aspecto educacional.

No Brasil, os estudos nesse campo continuam sendo raros. Após a abertura política, ocorrida em 1985, pudemos observar o gradual crescimento de pesquisas acadêmicas voltadas à história militar e ao seu ensino, principalmente, relacionadas ao Exército Brasileiro. Lentamente e sob pressão social, arquivos militares passaram a ser abertos ao público em geral para consulta a documentos diversos. Apesar disso, ainda há pouquíssimas pesquisas históricas relacionadas à educação na Marinha e, muito menos, na Aeronáutica.

Acreditamos que a pesquisa na área da história da educação militar possa revelar a influência do campo militar na educação brasileira e vice-versa. Dessa forma, no que se refere à importância do CME/UNIFA, podemos verificar que este Centro oferece a possibilidade, por exemplo, de ampliar os conhecimentos acerca do espaço escolar, da história dos uniformes, dos manuais escolares, dos materiais escolares, dos métodos de ensino, dos prédios escolares, dos museus escolares, do cinema escolar, das instituições de atendimento à infância pobre, da formação das mentalidades militares, e de outros aspectos que nos permitem compreender as práticas educativas militares adotadas ao longo do tempo.

Por outro lado, é sabido que a pesquisa científica nesse campo é imprescindível à elaboração de uma nova política educativa militar e de projetos de reforma pedagógica nesse contexto. Sem ela, é impossível melhorar a educação militar atual. 
Enfim, se não preservarmos a memória desse ensino, será muito difícil investigá-lo, assim como os seus sujeitos históricos.

\begin{abstract}
Numerosos livros constituem este acervo [o do CME/UNIFA] e "se hospedam" em prateleiras e armários à espera de estudos e pesquisas. Portadores de discursos variados, alimentadores de imaginários, são fontes para o estudo da escola já que são elementos imprescindíveis na constituição de uma cultura escolar. (CUNHA, 2006)
\end{abstract}

\title{
Referências
}

BICCAS, Maurilane de Souza; SALVADORI, Maria Ângela Borges. Centros de documentação e memória da educação: perspectivas de pesquisa para história da educação. Horizontes, v. 23, n. 2, jul./dez. 2005, p. 147-155.

BRASIL. Decreto $n^{\circ} .88 .749$, de 26 de setembro de 1983. Institui a Universidade da Força Aérea Brasileira, extingue cargo privativo de Oficial-General e dá outras providências. Fonte: Centro de Memória do Ensino Militar ( $C M E)$, da Universidade da Força Aérea (UNIFA).

CARDOSO, Maria Luiza (Org.). Campo dos Afonsos: 100 anos de história da aviação brasileira. Rio de Janeiro: Universidade da Força Aérea, 2012.

CUNHA, Maria Teresa Santos. Assim nas páginas como nas margens. Marcas do ler em livros escolares do acervo do Museu da Escola Catarinense (décadas de 20 a 70 do século $\mathrm{XX}$ ). Anais do IV Congresso Brasileiro de História da Educação. Tema "A educação e seus sujeitos na história”, realizado na Universidade Católica de Goiás (UCG), de 5 a 8 Nov. 2006.

VIÑAO FRAGO, António. Fracassan las reformas educativas? In: SOCIEDADE BRASILEIRA DE HISTÓRIA DA EDUCAÇÃO (Org.). Educação no Brasil. Campinas, SP: Autores Associados, 2001.

GONÇALVES, Nadia Gaiofatto. A escola e o arquivo escolar: discutindo possibilidades de interlocução entre atividades de ensino, pesquisa e extensão. Anais do IV Congresso Brasileiro de História da Educação. Tema "A educação e seus sujeitos na história", realizado na Universidade Católica de Goiás (UCG), de 5 a 8 Nov. 2006. 
HARTOG, François. Tempo e patrimônio. Varia Historia, Belo Horizonte, vol. 22, $\mathrm{n}^{\circ} 36$, jul./dez. 2006, p.261-273.

SOUZA, Rosa Fátima de. Preservação do patrimônio histórico escolar no Brasil: notas para um debate. Revista Linhas, Florianópolis, v. 14, n. 26, jan./jun. 2013, p. 199-221.

TESSITORE, Viviane. Como implantar centros de documentação. São Paulo: Arquivo do Estado, Imprensa Oficial, 2003. (Projeto Como Fazer, 9).

VIDAL, Diana Gonçalves. Cultura e prática escolares: uma reflexão sobre documentos e arquivos escolares. In: SOUZA, Rosa Fátima e VALDEMARIN, Vera T. (Orgs.) A cultura escolar em debate: questões conceituais, metodológicas e desafios para a pesquisa. Campinas, SP: autores Associados, 2005.

VIDAL, Diana Gonçalves. Fim do mundo do fim: Avaliação, preservação e descarte documental. In: FARIA FILHO, Luciano Mendes de (Org.). Arquivos, fontes e novas tecnologias: questões para a história da educação. Campinas, SP: Autores Associados; Bragança Paulista, SP: Universidade São Francisco, 2000. (Coleção memória da educação)

Recebido em: 21/03/2014 Aprovado em: 05/05/2014

Universidade do Estado de Santa Catarina - UDESC Programa de Pós-Graduação em Educação - PPGE Revista Linhas Volume 15 - Número 28 - Ano 2014 revistalinhas@gmail.com 